\title{
Introducing The Forum
}

\author{
Walter A. Rosenbaum
}

Published online: 10 November 2013

(C) AESS 2013

In this issue, we present a new Journal of Environmental Studies and Sciences feature called The Forum. The Forum creates opportunities for reflection, lively debate, and insight based on informed opinion about all aspects of contemporary interdisciplinary environmental studies and sciences. Here, a reader will find essays, op-eds, letters to the editor, and film reviews, all intended to promote engaging discussion.

The essays will be a regular feature of the Forum. These essays, often solicited from senior scholars and professionals in interdisciplinary environmental studies and practice, are peer-reviewed for timeliness, accuracy, and cogency. They create contrasting, sometimes controversial, perspectives about critical issues in contemporary environmental studies, science, and professions.

The initial essays in this issue present early, incisive explorations of a controversial and innovative public policy recently proposed by the internationally known climatologist James Hanson. He proposes that mitigating global climate change requires that most of the remaining international fossil fuel reserves must remain in the ground, and this can be achieved by pricing carbon through a "fee-and-dividend" strategy. This plan would tax carbon at various points of entry into a national economy, such as seaports. The fee would then be returned directly to consumers in relation to their carbon consumption, thus providing an incentive to move away from fossil energy sources. Is this practical, or even plausible? What will be the actual impact? We all know about the iron law of unintended consequences. Here, three scholars in two essays evaluate the notion of carbon pricing, its distributional problems, and alternatives.

Preface for the new Forum section of the journal to appear in the March 2014 issue

W. A. Rosenbaum ( $\square)$

University of Florida, Gainesville, FL, USA

e-mail: tonyros@ufl.edu
In "Two World Views on Carbon Revenues," Dallas Burtraw and Samantha Sekar, policy specialists associated with Resources for the Future, maintain that carbon pricing would be more efficient than the prescriptive regulation of greenhouse gases. From this perspective, they ask the important question concerning to whom should this additional revenue go? While Hanson's fee-and-dividend would allocate the funds straight to consumers, Burtraw and Sekar argue that the rightful recipients depend on how we think of the atmospheric commons. Recipients of the funds could, for example, be nation states if the atmosphere is determined to be state property; then the tax or fee could go to governmental budgets. However, if the atmosphere is conceived as the property of individuals in common, then a dividend to individuals may be politically expedient but complicated by the global nature of such a commons.

In a second essay, "Climate and Economic Storms of Our Grandchildren," international energy expert and consultant John "Skip" Laitner, currently president-elect of AESS, uses research he and others conducted for the American Council for an Energy-Efficient Economy to analyze the idea of US carbon pricing. Laitner begins with the premise that economic welfare in the USA is hampered by dreadful energy inefficiency. This inefficiency is so pervasive that Laitner concludes through a thoughtful experiment that the USA could have reduced its 2012 energy consumption in half to 1980 levels, and also lowered carbon emissions below 1980 levels, while still creating a stronger economy. What is the best way to accomplish this task, far more ambitious than the now-expired Kyoto Protocol? Laitner argues that non-pricing programs, some of which need government investment and intervention to establish efficiency and behavioral feedbacks, will bring more options and value across the US economy. These benefits include economic savings for households, hundreds of thousands of jobs, and deep cuts in greenhouse gases.

These essays illustrate the quality of informative and accessible insight we hope to bring to Journal of Environmental 
Studies and Sciences readers and in this instance, to those who may not be expert in economics but to whom carbon policies are important. In the future, the Forum will be addressing other concerns such as the role of theory in environmental studies and sciences, the future of food, and a discussion about the advances of ecofeminism with the goal of adding expert thinking to the interdisciplinary community. 